\title{
RESENHA
}

\section{A QUESTÃO PÚBLICA DA ESCOLA NA CONTEMPORANEIDADE}

\author{
Luziane Said Cometti Lélis'
}

GALLO, Sílvio; MENDONÇA, Samuel (Orgs.). A escola: uma questão pública. São Paulo: Parábola, 2020, 224 p., ISBN:978857934180-9.

A obra "A escola: uma questão pública" representa o primeiro volume do díptico "Escola: problema filosófico", organizado a partir do III Congresso da Sociedade Brasileira de Filosofia da Educação (SOFIE), apoiado e financiado pela Coordenação de Aperfeiçoamento de Pessoal de Nível Superior (CAPES) e Conselho Nacional de Desenvolvimento Científico e Tecnológico (CNPQ), na perspectiva de afirmar a escola enquanto espaço de caráter público, privilegiado e acolhedor de cidadãos em todas as suas diferenças, inacreditavelmente, ameaçado pelo contexto social neoliberal que institui a governança empresarial como nova forma de saber e poder.

A temática tratada, apesar de não ser ignorada pela filosofia da educação, não teve dedicação devida durante as últimas três décadas, ao menos na produção brasileira. Registra-se uma publicação em 2013 no Brasil, dos filósofos belgas Jan Masschelein e Maarten Simons, que fazem uma "defesa da escola" tomada como questão pública, recuperando o sentido etimológico da palavra grega skholé, tempo livre, nas condições do mundo contemporâneo e as questões políticas e sociais que isto implicaria; e, na França, o livro "L'École, question philosophique, do filósofo Denis Kamboucher, defendendo a necessidade de pensar a instituição escolar como questão filosófica.

Os escritos dos filósofos da educação da obra resenhada são de várias universidades brasileiras que recorreram ao instrumental conceitual filosófico para pensar a instituição escolar na contemporaneidade, sua problemática, suas políticas, seus atores (professores e alunos), seus projetos, seus sentidos, em diferentes dimensões e perspectivas teóricas, distribuídos por onze capítulos, estruturados em três grandes partes: Escola e formação; Políticas da escola e Problemas da escola.

A primeira parte intitulada Escola e formação é composta por três capítulos dedicados à relação da escola com a formação humana, sob diferentes vieses filosóficos. O capítulo "A filosofia, a escola e o experimentum formativo: a libertas como cultivo da soberba inflamada", escrito por Cláudio A. Dalbosco, ressalta a tarefa da filosofia em pensar a SEMEC/Belém. ORCID: https://orcid.org/0000-0002-7870-9023. E-mail: Iuziane.bim@gmail.com 
escola como experimento formativo, desvencilhada da metafísica, num registro pós-humanista, sob as lentes do pensamento de Foucault. $O$ autor percorre a tradição grega da skholé, latina do otiom e alemã da Bildung para retomar o sentido originário do "tempo livre", voltado para o cultivo da alma - governo ético de si para o bom governo dos outros -, que sempre ocorre na companhia do outro e afirma que no momento contemporâneo, em que o neoliberalismo institui a governança empresarial como nova forma de poder, dando origem às novas formas de subjetividade, orientadas pelos dispositivos da competição, eficiência e lucratividade, a filosofia tem a tarefa de retomar a educação como preparação no sentido instructio permanente e exigente cultivo de si mesmo para o controle de sua soberba inflamada e do domínio alheio sobre si. Pensar a escola orientada pelo libertas - experimento formativo conduzido pelo mestre com o envolvimento do discípulo - é indispensável para o enfrentamento da soberba humana, ainda mais inflamado pelo modo e formas de assujeitamento da vida neoliberal. Na perspectiva do libertas, a escola pode ir na direção contrária ao ensino de competências e habilidades, tão requeridas pelo empreendedorismo, para formas mais cooperativas e solidárias da vida.

Em "Resistências ao cotidiano escolar de exceção: o ingovernável, a desobediência e o julgar reflexivo", Pedro A. Pagni analisa o contexto político do capitalismo avançado no neoliberalismo à brasileira, para compreender as formas de controle de subjetividade e de subordinação desse processo na escola, dando destaque à servidão maquínica apontada por Maurício Lazzarato. É na conjuntura biopolíitca que o corpo deixa de agir com reflexão para agir por reflexo, passando a ser objeto de controle mais cortante pela servidão maquínica, que atua sobre a subjetividade do indivíduo, reduzindo-o a um corpo individuado. Nesse contexto, a atenção é dada para aqueles corpos desviantes ou "ingovernáveis", em que a desobediência se torna uma atitude humanizadora. Pagni apresenta a escola como um problema filosófico no presente, atravessada por focos de resistência em que seus atores afrontem o funcionamento atual, fomentando processos de subjetivação que contrapõem-se aos estados de dominação, capturados pelos dispositivos do biopoder. Assim, na viabilidade de atuação dos sujeitos no seu processo formativo, apela para a filosofia da educação como ferramenta imprescindível para pensar a educação e a escola.

No texto "Ser professor: cerceamentos paradigmáticos e armadilhas ideológicas", o autor Marcos Antônio Lorieri, em diálogo com outros filósofos da educação, provoca a pensar o "ser professor" a partir de dois aspectos problemáticos: os cerceamentos paradigmáticos e as armadilhas ideológicas (falseamentos da realidade) que merecem atenção reflexiva e crítica da filosofia. Mostra a maneira como a filosofia da educação pode 
oferecer subsídios aos educadores na superação desses elementos que se apresentam como problemáticos no âmbito da educação. Afirma e reafirma a imagem do educador como profissional que possui intencionalidade clara do seu papel e da sua posição política. Portanto, evidencia a necessidade de uma formação filosófica sólida, articulada a outros conhecimentos científicos para, que os docentes possam refletir sobre sua prática e manter uma vigilância crítica contínua diante da visão estreita da profissionalidade, espontaneísta ou simplória e de enviesamento ideológico de sua ação educativa.

A segunda parte, "Políticas da Escola", destaca, em seus quatros capítulos, o contexto da política neoliberal no qual estamos imersos, mostrando por um lado, a subsunção da instituição escolar à lógica do mercado e, por outro lado, as possibilidades de resistência e ação política. $O$ autor do capítulo "A escola contemporânea e a desertificação institucional: o demérito da res publica", Alexandre Filordi de Carvalho analisa, a partir de 2008, o contexto contemporâneo de precariedade produzida pelo capitalismo neoliberal nos diversos campos, localizando a escola num processo de desertificação de seu valor simbólico e real e de dissonância de status, fabricada como resposta ao demérito da res publica. Assume a desertificação institucional sofrida pela escola como múltiplo contexto e efeito complexo, destacando três dimensões: os reflexos da herança doutrinária do capitalismo neoliberal; as estratégias de consolidação de uma "ordem subjetiva" e o desprezo pela coisa pública. Aponta as articulações políticas dos estudantes secundaristas como ato de resistência à maquinaria neoliberal, além de apostar em estratégias afirmativas da escola e saberes assujeitados a serviço da dimensão pública.

Em "O governo biopolítico do tempo escolar", Divino José da Silva parte dos argumentos de Masschelein e Simons em defesa da escola de tempo livre (skholé) em contraposição à racionalidade e à temporalidade que governam a escola contemporânea, para refletir sobre os entraves que impedem sua realização. Evidencia a urgência de pensar os efeitos do "governo da vida" orientada e ordenada, seguindo o modelo da empresa biopolítica, ampliação do controle não somente do tempo, mas da vitalidade (corpo, órgão, cérebro) manipuladas pelas tecnologias da informação -, e seus reflexos no tempo escolar. A partir da noção de "sociedade do desempenho" desenvolvida por Han, analisa como o capital se apropria da vitalidade e da força produtiva, mobilizando nosso tempo para o trabalho, num regime de "servidão maquínica", que parece não deixar tempo para reflexão e a elaboração do pensamento, produzindo sua monetarização. Exatamente num contexto de exaustão do corpo, pelo excesso de disciplina, que emerge a resistência e a necessidade de pensar

Revista Exitus, Santarém/PA, Vol. 11, p. 01 - 08, e020149, 2021. 
os efeitos do governo do tempo e seus reflexos no governo do tempo escolar sobre os processos formativos perspectivados pela escola de tempo livre.

Pedro Goergen analisa o desafio do processo formativo no mundo em que toma o mercado como a referência de tudo e, a mercadoria difundida pela mídia, a geradora de necessidades e de desejos. Nesse contexto, o autor evidencia a redução dos pressupostos humanistas de formação a um trabalho subserviente aos interesses do sistema econômico, no capítulo intitulado "O sentido da educação na sociedade contemporânea". Ressalta que num modelo performático, embasados na competitividade e rivalidade, a educação compromete o sentido formativo social, ético, cooperativo e de reconhecimento do outro para formar indivíduo útil e adequado às expectativas do mercado. Diante da ausência de um núcleo humanista, esteio agregador do sentido da pessoa humana, que o deixa vulnerável ao apelo e interesse do sistema econômico, coloca como questão central da educação na contemporaneidade e da filosofia da educação, o resgate da figura do outro na constituição da subjetividade humana - na ideia do comum, na perspectiva de surgir novo conceito de autonomia, tributária da cultura e construída na práxis histórico-dialógica-humana.

Em "A autogestão nas escolas ocupadas em Paris [1968] e em São Paulo [2015]", Paulo Henrique Fernandes Silveira busca a sincronia entre dois movimentos estudantis diacrônicos, que num ato de resistência ao realizarem a ocupação das instituições educacionais, colocaram em prática a autogestão democrática. O autor mostra que os protestos e as reinvindicações dos estudantes universitários (Paris) e secundaristas (Brasil) se diferem pelas condições políticas e educacionais de seus países, mas identifica muitas semelhanças marcadas por contestações culturais e lutas antiautoritárias: questionavam as dificuldades enfrentadas pelo cotidiano, 0 rígido sistema hierárquico de poder; combatiam os governos e as medidas autoritárias e ditatoriais; opunham-se às guerras e às intervenções colonialistas e imperialistas; alternavam as estratégias de luta e utilizam instrumentos de comunicação como divulgação das suas ideias e demandas, sendo impressos (em 1968) e eletrônicos (em 2015); não aceitaram lideranças e nem participação de partidos políticos.

A terceira e última parte da obra "Problemas da Escola", destaca nos quatros capítulos os desafios enfrentados pela escola contemporânea, que sem a pretensão de oferecer soluções definitivas, apoiam em reflexões filosóficas para sustentar uma prática emancipatória. A autora de "Escolas e problemas: uma política vitalista", Cintya Regina Ribeiro, na companhia filosófica deleuzo-guattariana e nietzschiana, pensa a escola como um problema qualificado, mobilizando o conceito de percepção molecular - na qual emerge o imperceptível -, capaz de lidar com a coexistência vitalista 
das forças de determinação e indeterminação que se atritam em condição de imanência. Trata-se de vislumbrar o problema de escola, não como um ser, mas como modo de ser, um modo de existir, que pulsa, vive, ressoa modos de vida disputando existência. A política vitalista toma a vida como detentora de valor em si mesmo, não podendo ser reduzida a qualquer condição que the seja alheia. Nessa perspectiva, problemas clamam menos por supostas soluções e mais por pensamentos sensiveis que possam extrair das forças problemáticas as linhas pulsantes do traçado cartográfico de uma escola.

No capítulo "Uma escola filosófica popular?" Walter Omar Kohan apresenta as principais críticas atribuídas à escola na modernidade, e algumas vozes em sua defesa. Retoma a tradição de se fazer escola na América do Sul do século XIX para pensar e afirmar uma escola filosófica e popular no século XXI. A escola filosófica popular - Colégio de Órfãos e Garotos de Carpintaria - inventada pelo venezuelano Simón Rodríguez em Chuquisaca, rompe com a ordem social hierárquica, afirma a igualdade como princípio, abre espaço para a vida em comum numa condição de cidadão, universaliza o espaço de suspensão e profanação, está obstinada à pergunta. A escola filosófica e popular de Rodríguez é tomada como um convite para pensar a escola hoje, seus problemas, seus tempos e espaços, a partir de outra ordem que esteja mais sensivel e atenta aos que habitam a terra.

O texto de Julio Groppa Aquino "O mau encontro entre escola e humanismo" elege a companhia intelectual de Michel Focault como principal referência para problematizar a escola e o humanismo, visto como "mau encontro" no sistema capitalista, dada a fragilidade filosófica e embaraços políticos, mesmo tendo constatado o slogan tão onipresente e enigmático no campo educativo contemporâneo, como prática da liberdade. Analisa as contribuições teóricas de Ivan Illich e Paulo Freire, como responsáveis pela "virada crítica" da educação a partir da década de 1970, com ênfase no humanismo - defesa inconteste da autonomia e da liberdade dos educandos, apesar das suas diferenças conceituais enquanto Illich trata de desescolarizar a sociedade; Freire, defende a reconquista política da escola -, para mostrar a pertinência de perspectivar as vicissitudes desse ideário. Mostra que a racionalidade neoliberal absorve o legado crítico do pensamento humanista, realizando uma espécie de correspondência distorcida e reduzida ao exercício de liberdade pedagógica psicologizada. Vislumbra uma prática desembaraçada de qualquer projeção humanista.

Num tempo em que as instituições públicas são objetos de descrença pela sociedade e ataques de elites conservadoras, Lílian do Valle dedica no 
seu texto "Filosofia da educação e escola pública" romper com a naturalização da singularidade de um dos pilares do projeto democrático moderno - a escola pública. É a invenção democrática moderna que engendra a necessidade de criação de uma instituição verdadeiramente pública voltada para a formação dos cidadãos, como sustentáculo da sociedade, se diferenciando das práticas de educação familiar e escolas dominicais religiosas. A autora problematiza os múltiplos detratores que propagam o conservadorismo de uma escola excludente, embalados pelos discursos encantatórios da expansão da educação à distância e a proclamação da formação espontânea servida no contexto familiar - homeschooling. Colocar em risco a escola pública que representa um espaço diferente, privilegiado e coletivo no acolhimento de todos em suas diferenças, é colocar em risco a própria democracia. Assim, a escola pública precisa dos recursos da filosofia para se repensar, propor, ser e atuar na defesa da sociedade democrática.

O conjunto de textos desta obra apresenta argumentações sólidas, ancoradas em robustos aportes teóricos e, com algumas possibilidades de exercício do pensamento da filosofia da educação sobre a instituição escolar na contemporaneidade, em que provoca uma problematização e uma atuação mais inquiridora dos seus sujeitos, enquanto agentes de sua construção cotidiana.

A totalidade dos escritos analisa o contexto da política neoliberal que fomenta processos de subjetivação de estados de dominação, produzindo formas de sujeição dos indivíduos às orientações do mercado, subsumida pela escola na atualidade, sem todavia, deixar de descortinar o falseamento da realidade que se impõe ao ambiente escolar para anunciar como ato de resistência, o resgate de uma formação humana na direção contrária do empreendedorismo para formas mais cooperativas, solidárias e coletivas.

Nessa empreitada, de afirmação da escola, como espaço inventado, democrático e público, que pulsa modos de vidas diversos em seu modo próprio de existir, conclama os docentes para uma reflexão e vigilância contínua de sua prática diante da visão estreita da profissionalidade, do risco da precariedade da formação, espontaneísta ou simplórias da ação educativa. Desse modo, a leitura desta obra é imperiosa ao conjunto de educadores que busca desnaturalizar as práticas homogeneizadoras engendradas pelo capital e, em contrapartida, militar no árduo projeto de manter a escola enquanto espaço público de formação humana, coletiva e emancipatória.

\section{Referências}

GALLO, S.; MENDONÇA, S.(Orgs.). A escola: uma questão pública. São Paulo: Parábola, 2020, 224 p., ISBN:978857934180-9.
Recebida em: 03 de setembro de 2020. Aprovada em: 22 de março de 2021. Publicada em: 26 de abril de 2021. 